\title{
AOR
}

Selected Papers of \#AolR2020:

The $21^{\text {st }}$ Annual Conference of the Association of Internet Researchers

Virtual Event / 27-31 October 2020

\section{THE DATAFICATION OF CHILDHOOD: EXAMINING CHILDREN'S AND PARENTS' DATA PRACTICES, CHILDREN'S RIGHT TO PRIVACY AND PARENTS' DILEMMAS}

Giovanna Mascheroni,

Università Cattolica del Sacro Cuore, Milan, Italy

Sonia Livingstone, LSE, London, UK

Mariya Stoilova, LSE, London, UK

Rishita Nandagiri, LSE, London, UK

Tijana Milosevic, Dublin City University

Aldona Zdrodowska, National Information Processing Institute, Warsaw, Poland

Elisabeth Staksrud, University of Oslo

Andra Siibak, University of Tartu

Marit Sukk,

University of Tartu

Mascheroni, G., Livingstone, S., Stoilova, M., Nandagiri, R., Milosevic, T., Zdodrowska A., Staksrud, E., Siibak, A., Sukk, M., Zaffaroni, L. G., Cino, D., \& Wartella, E. (2020, October 28-31). The datafication of childhood: examining children's and parents' data practices, children's right to privacy and parents' dilemmas. Panel presented at AolR 2020: The $21^{\text {th }}$ Annual Conference of the Association of Internet Researchers. Dublin, Ireland: AoIR. Retrieved from http://spir.aoir.org. 
Lorenzo Zaffaroni,

Università Cattolica del Sacro Cuore, Milan, Italy

Davide Cino,

Università Cattolica del Sacro Cuore, Milan, Italy

Ellen Wartella,

Northwestern University

\section{Introductory statement}

In the age of continuous data collection and algorithmic predictions, children's privacy seems threatened by the variety of surveillance and data practices in which parents, institutions, corporations and children themselves engage. The vast amount of data routinely collected about children as they grow up include data shared online, whether by children themselves (social media updates, web searches and browsing, data traces of their internet and smartphone use) or their parents (sharenting practices); data shared in the home, like conversations and environmental data captured by internetconnected devices such as smart speakers and internet connected toys; data shared outside the home, including educational and school apps, biometric data in schools and/or airports and stations, health data and medical records, geo-location apps or wearables, etc. Data can be knowingly shared with others, or "given off" as traces of online activities, and even inferred by algorithms that profile, classify and predict users' behaviour.

This panel on the datafication of childhood draws together a number of leading scholars in this area of research to explore questions and issues associated with children's privacy online as both a protective and enabling right. The collection of papers in this panel contribute empirical data and theoretical insight on a range of relevant topics in the study of the datafication of childhood from the perspective of both children and parents. Based on qualitative and quantitative methods, the individual contributions to the panel illuminate the situated nature of data practices, their embeddedness in diverse contexts and practices of meaning-making through which children and parents negotiate online privacy.

The first paper draws on qualitative data collected from 150 children aged 11 to 16 from selected schools in the UK and to some of their parents. The findings problematise both the common-sense assumption that children and teenagers do not care for their online privacy, and the myth of the digital natives as competent users, by showing how young people struggle to protect their online privacy despite employing a range of dataficationevasive strategies.

The second paper examines survey data collected in Norway on a representative sample of 9-17-year-old Internet using children and one of their parents/caregivers in order to test the "privacy paradox". The paper aims to assess whether privacy concern is associated with the amount of personal information about themselves that children disclose online, or with their experience of sharenting-related breaches. Further, it also 
investigates whether children's level of privacy concern is related to their parents' preoccupation with online privacy.

The third paper employs a mixed-method approach (semi-structured interviews and qmethodology) to explore the surveillance imaginaries and practices of Estonian parents $(\mathrm{N}=20)$ who use tracking technologies for keeping an eye on their children, as well as their 7-13 year-old children $(\mathrm{N}=20)$ who are aware of such intimate surveillance. The paper provides a typology of both children's and parents' perspectives related to the use of tracking technologies.

The fourth paper analyses survey data collected from a national representative sample of Italian parents of 0- to 8-years-old children to map the data-practices in which parents and young children engage, and the availability of internet-connected devices (smart speakers, Internet of Toys, other loTs) in Italian homes. The paper aims to identify the antecedents and consequences of the datafication of children's lives, and develop a typology of families based on parents' intimate surveillance practices, parenting imaginaries and children's use of digital media and loTs.

The fifth paper explores how parents govern their children's social media presence when not only parents, but also adults from external systems share about them. The paper draws on a survey of 300 American parents to show how parents are divided between conflicting social expectations and the desire to protect their children's privacy. It also highlights a double loss of agency which may result from sharenting: children lack control of the process, but parents too may lose track of their children's digital footprints when it is other adults who share about the child.

\section{PAPERS}

\section{“I WANT TO KEEP IT TO MYSELF”: HOW WELL DO CHILDREN EVADE ONLINE DATAFICATION TO PROTECT THEIR PRIVACY?}

Sonia Livingstone, LSE, London, UK

Mariya Stoilova, LSE, London, UK

Rishita Nandagiri, LSE, London, UK

Children's autonomy and dignity as actors in the world depends on both their freedom to engage and their freedom from undue persuasion or influence. In a digital age in which many everyday actions generate data - whether given by digital actors, observable from digital traces, or inferred by others, whether human or algorithmic - the relation between 
privacy and data online is becoming highly complex. In such complicated digital ecology, how do children evade online datafication to protect their privacy? Do they have the knowledge, media literacy and digital skills to counteract a privacy-invasive model? As part of our ICO-funded project on Children's Data and Privacy Online, we spoke to 150 children aged 11 to 16 from selected schools in England, Scotland and Wales and to some of their parents, asking about their privacy and data sharing practices, understanding of the digital ecology and struggles with privacy protection.

This paper presents our findings and argues that children are engaging in a range of datafication-evasive strategies and take a stand against invasions of their privacy by both individuals and companies. Yet, their efforts are limited - more by their awareness than their skills, but mostly within the boundaries of a data-commercialisation environment. Still, how effective are children in their strategies to manage interpersonal privacy vs managing commercial privacy? Firstly, children care about their privacy and are outraged that companies use their data 'behind the scenes', often demanding data minimisation, more visibility of data processing, and more control over their digital footprint. On the interpersonal level, they expect their friends and families to respect their privacy and follow a mutually-acceptable code of practice.

Secondly, children are generally protective of their information and often reply that they would like to keep to themselves various types of personal data, such as where they go, who they meet and what they search online. Children also engage in a wide range of strategies to keep their devices, online profiles and personal information safe from unwanted interference. Yet, children mostly focus on strategies to manage interpersonal privacy, rather than commercial. Thirdly, children can be quite evasive online - they move quickly between different apps and platforms, switch between several accounts and channels with carefully selected audiences, know how to remove their traces and to alter data, by providing fake information, changing textual descriptions, removing tags, altering images, deleting or blocking content. Quite effective in terms of interpersonal privacy, children seek to apply the same strategies to commercial contexts - with varying effects.

While, children are actively learning about the online environment, drawing on a wide range of social, educational and online resources, their privacy protection is not without limits. We conclude the paper arguing in favour of system-level privacy-by-design changes which can support and reinforce children's rights and privacy.

\section{THE CHARACTERISTICS OF PRIVACY-MINDED CHILDREN IN THE CONTEXT OF PRIVACY PARADOX: NORWEGIAN CASE STUDY}

Tijana Milosevic, Dublin City University

Aldona Zdrodowska, National Information Processing Institute, Warsaw, Poland 
Giovanna Mascheroni,

Università Cattolica del Sacro Cuore, Milan, Italy

Elisabeth Staksrud,

University of Oslo

With an ever-growing use and variety of digital devices, most recently the Internet of Things, children's and family privacy is an important topic with many under-researched aspects (Livingstone, Stoilova, Nandagiri, 2019). Although children and adolescents might be more likely to share greater amounts of personal information than adults, and to apply more lenient privacy settings on social media (Walrave, Vanwesenbeeck, \& Heirman, 2012), studies have also shown that young people tend to care about their privacy (see e.g. boyd, 2014; Marwick \& boyd, 2014).

In this article, we examine "privacy concern" as a possible source of motivation for privacy protecting behaviors. According to the widely used Communication Privacy Management (CPM) theory (Petronio, 2002, 2015), higher privacy concern leads to employing more restrictive privacy behaviors. Nonetheless, previous research has also identified the concept of "privacy paradox" (De Wolf cf. Acquisti \& Gross, 2006; Hargittai \& Marwick, 2016), which proposes that despite reported privacy concern, young people nonetheless disclose large amounts of information about themselves. A possible explanation is in the feeling of a lack of control in networked environments generating "apathy" and "cynicism" and the impression that "privacy violations are inevitable" (Hargittai \& Marwick, 2016, p. 3752). We test the paradox by studying whether children who report greater privacy concern actually disclose more or less personal information about themselves; or otherwise engage in behaviors that might jeopardize their privacy (e.g. by using wearable devices and the Internet of Things, which might expose them to increased levels of data collection for commercial purposes).

We further examine whether children whose parents or caregivers share significant amounts of information about them, and children who have experienced sharentingrelated breaches (such as being upset about what their parents have posted online) are more likely to be concerned about their privacy than other children. Following CPM, such breaches, which the theory terms as "turbulence" would lead to higher privacy concern. Finally, we also test whether children whose parents display higher levels of privacy concern tend to be more concerned about their privacy as well.

We study these questions on a nationally representative sample of 9-17-year-old Internet using children from Norway and one of their parents/caregivers, conducted as part of the EU Kids Online project in 2018. As a case study, Norway is a country where the use of digital technology among youth is very high, as confirmed by the most recent analyses on nationally representative samples of children in 19 European countries; and so is exposure to risks (Smahel et al., 2020; Helsper et al., 2013). While children's independent smartphone and social media use starts early, children also tend to enjoy significant family, social and policy-level support for safe digital media use, as compared to other European countries. 
With this in mind, we ask the following research questions:

RQ1: What are the characteristics of children who report grater levels of concern for their privacy online and with digital technology?

RQ1a: Are children with higher digital skills more worried about their privacy (because they are more aware of the dangers)?

RQ1b: Are children who have experienced privacy or data-protection-related harms more likely to report privacy concerns?

RQ2: What are the characteristics of families of children who report grater levels of concern for their privacy online and with digital technology?

RQ2a: How are parental attitudes to privacy online and with digital technology related to children's levels of concern for their privacy?

RQ2b: What is the relationship between parental digital skills and children's levels of concern for their privacy?

RQ3: Do children who report higher privacy concern share more information about themselves online than children who report lower concern?

RQ3a: Are children who report higher privacy concern less likely than other children to use wearable devices and the Internet of Things devices?

\section{Sampling and method}

This study relies on a nationally representative survey sample of Internet-using children in Norway. The data was collected between June and October 2018 within the EU Kids Online research project. 1001 children of both sexes, aged from 9 to 17 years, were interviewed via CASI method. The data was collected by Ipsos Mori. $47.1 \%$ of the sample was female, Mage=13.3. The sampling frame was stratified by the economic characteristics of municipalities as well as the number of 9 to 17-year-old children who lived there. Respondents were initially recruited by telephone, followed by face-to-face interviews at home. Respondents' anonymity and confidentiality were secured. The data collection was approved by the Norwegian national Data Authority (Datatilsynet), and followed procedures established by the National Ethical Committees for Social Science and Humanities and by the Norwegian Center for Research Data (NSD). Informed consent was obtained from each parent and each child that participated.

\section{Data analyses and initial results}

In order to verify determinants of higher levels of privacy concern in children and teenagers, we conducted a series of logistic regression analyses in the proportional odds model, controlling for child demographics and psychological characteristics. Findings indicate that privacy breaches such as sharenting, as well as general risk experiences significantly predict higher levels of privacy concern. Furthermore, children 
who declare having found themselves in a situation where they could use the privacyrelated advice (e.g. on sharing personal information online) are also more concerned about their privacy online. Additionally, parental level of privacy concern seems to have a modelling effect on a child's attitude towards privacy online. Preliminary analyses into privacy paradox did not provide support for nor evidence against the effect.

\section{References}

Acquisti A and Gross R (2006) Imagined communities: Awareness, information sharing, and privacy on the Facebook. In: Danezis G and Golle P (eds) Privacy Enhancing Technologies. Berlin: Springer, pp. 36-58.

Baruh L, Secinti E and Cemalcilar Z (2017) Online privacy concerns and privacy management: a meta-analytical review. Journal of Communication 67(1): 26-53.

De Wolf, R. (2019). Contextualizing how teens manage personal and interpersonal privacy on social media. New Media \& Society, 1461444819876570.

Hargittai E and Marwick A (2016) "What can I really do?" Explaining the privacy paradox with online apathy. International Journal of Communication 10: 3737-3757.

Helsper, E. J., Kalmus, V., Hasebrink, U., Sagvari, B., \& De Haan, J. (2013). Country classification: Opportunities, risks, harm and parental mediation.

Livingstone, S., Stoilova, M., \& Nandagiri, R. (2019). Children's data and privacy online: growing up in a digital age: an evidence review. Retrieve: http://www.Ise.ac.uk/mediaand-communications/assets/documents/research/projects/childrens-privacyonline/Evidence-review.pdf

Petronio S (2002) Boundaries of Privacy: Dialectics of Disclosure. Albany, NY: State University of New York Press.

Petronio, S. (2015). Communication privacy management theory. The International Encyclopedia of Interpersonal Communication, 1-9.

Smahel, D., MacHackova, H., Mascheroni, G., Dedkova, L., Staksrud, E., Olafsson, K., ... \& Hasebrink, U. (2020). EU Kids Online 2020: survey results from 19 countries.

Staksrud, E. and Ólafsson, K. (2019). Access, use, risks and opportunities: Norwegian children on the Internet. Oslo: University of Oslo. Retrieved from:

https://www.hf.uio.no/imk/english/research/projects/eu-Kids-onlineIV/publications/20190701 euko2018 summary eng.pdf

Walrave, M., Vanwesenbeeck, I., \& Heirman, W. (2012). Connecting and protecting? Comparing predictors of self-disclosure and privacy settings use between adolescents and adults. Cyberpsychology: Journal of Psychosocial Research on Cyberspace, 6(1). 
UNDER THE PARENTAL TECHNO-GAZE:

REFLECTIONS AND EXPERIENCES OF ESTONIAN PRE-TEENS AND PARENTS WHO TRACK THEM

\author{
Andra Siibak, \\ University of Tartu \\ Marit Sukk, \\ University of Tartu
}

In the recent years the use of various digital parenting tools, e.g. other-tracking apps (Gabriels, 2016), has increasingly gained popularity among parents. Recent EU Kids Online survey findings report, for example, that $22 \%$ of Estonian parents are making use of various tracing technologies in order to keep an eye on their child (Sukk \& Soo, 2018).

Such tendencies indicate that present day parents are increasingly cultivating a specific plugged-in parenting routine, leading us to an age of "transcendent parenting" i.e. a practice "wherein parents must transcend every media consumption environment their children enter, their children's offline and online social interaction milieu and 'timeless time' as experienced in the apparent ceaselessness of parenting duties" (Lim 2018: 32). Although caring for children's well-being and safety has always been one of the main cornerstones of parenting philosophies, in contrast to the previous decades, the current "parental gaze has become technologized" (Howell 2010: 1). Some scholars even suggest that spying has become "an enhanced parenting tool" (Marx \& Steeves 2010: 205) as various digital parenting aids - from pregnancy apps and baby monitors to parental controls and tracking devices - have been brought to the market in the hopes of responding to the concerns and anxieties of parents.

In fact, the use of digital technologies have started to redefine the parents' and society's understanding of child rearing. Tama Leaver (2017: 8), for instance, has argued that we have reached a point in our society where offline parenting can be viewed as irresponsible and even reckless behavior. Furthermore, the concept of a "good" parent is also constantly being reshaped (Siibak 2019: 105), leading to the fact that many parents end up feeling that they are not fulfilling their parental role "correctly". Digital technologies and the processes related to them (e.g. mediatization), thus, affect the family dynamics and through that the roles of the family members in ways we are yet to fully unveil.

Although scholars (e.g. Siibak 2019; Mascheroni, 2018; Lupton \& Williamson, 2017) have become increasingly concerned about this growing (over)reliance on various digital technologies and parenting apps, empirical studies providing insights about children's views and experiences related to intimate surveillance exercised by parents, is currently lacking. In fact, in addition to a need to "document the diverse surveillance imaginaries and practices that are enacted in different families" (Mascheroni, 2018:10), 
Lupton and Williamson (2017) have argued for a need for child-oriented approach to dataveillance.

Our ongoing empirical study aims to contribute to this knowledge by carrying out semistructured individual interviews with Estonian parents $(\mathrm{N}=20)$ who use tracking technologies for keeping an eye on their children, as well as their 7-13 year-old children $(\mathrm{N}=20)$ who are aware of such intimate surveillance. Furthermore, we also made use of q-methodology, a method that is often used to reveal subjective attitudes and perspectives (Stephenson, 1953); to explore the surveillance imaginaries and experiences related to the use of tracking technologies.

All the participants in our study were asked to rank and sort a series of statements ( $N=28$ for the children; $N=36$ for the parents) related to the parental use of othertracking apps. The statements were built upon claims published by different media outlets and international press. The data collected enables us to propose a typology of both children's and parents' perspectives related to the use of tracking technologies.

Preliminary analysis indicates that this (over)protective and technologically moderated parenting stance has been caused by the competing demands of social, work-, and family life and the societal expectations about "good parenting". The pervasive attitude of the parents can be described as caring dataveillance (Lupton, forthcoming 2020): the parents wish to use every digital tool at their disposal to make sure their children are sticking to their daily routine and staying safe. In fact, parents in our sample tend to onesidedly focus on the protective and preventative features of tracking technologies, while almost entirely discarding the issues related to the children's privacy and digital rights.

The use of q-methodology has enabled us to reveal that although many children do not mind nor see any harm in such parental surveillance, there are children whose responses indicate a growing tension between care and the restriction of freedom such tracking evokes. Those children have also started to make use of different practices (e.g. "forgetting" their phones at home, switching them off, deleting the apps) in order to escape from this parental techno-gaze.

The findings of the study could provide important insight for parents and policy makers while aiming to foster accountability and responsibility of industry stakeholders.

\section{References}

Howell, J. (2010), Parents, Watching: Introducing Surveillance Into Modern American Parenting, University of lowa, lowa City, lowa, USA, http://dx.doi.org/10.17077/etd.a4wpg2r2.

Leaver, T. (2017). Intimate surveillance: normalizing parental monitoring and mediation of infants online. Social Media + Society, 3(2), 1-10.

http://dx.doi.org/10.1177/2056305117707192.

Lim, S. (2018). Transcendent parenting in digitally connected families: When the technological meets the social. In: Mascheroni, G. Ponte, C. \&. Jorge, A. (eds.), Digital 
parenting: The challenges for families in the Digital Age, The International Clearinghouse

on Children, Youth and Media, https://norden.divaportal.org/smash/get/diva2:1265024/FULLTEXT01. pdf\#page=21.

Lupton, D. (forthcoming 2020). Caring Dataveillance: Women's Use of Apps to Monitor Pregnancy and Children. In: Green, L., Holloway, D., Haddon, L., Stevenson, K., \& Leaver, T. (eds.) The Routledge Companion to Children and Digital Media. Routledge.

Lupton, D. \& Williamson, B. (2017). The datafied child: The dataveillance of children and implications for their rights, New Media \& Society, 19(5), 780-794.

http://dx.doi.org/10.1177/1461444816686328.

Marx, G. \& Steeves, V. (2010). From the beginning: Children as subjects and agents of surveillance, Surveillance \& Society, 7(3/4), 192-230.

http://dx.doi.org/10.24908/ss.v7i3/4.4152.

Mascheroni, G. (2018). Datafied childhoods: Contextualising datafication in everyday life, Current Sociology, p. 001139211880753 , http://dx.doi.org/10.1177/0011392118807534.

Siibak, A. (2019). Digital Parenting and the Datafied Child. In: Burns, T. \& Gottschalk, F. (Ed.). Educating 21st century children. Emotional well-being in the digital age (pp. 103-118). Paris: Educational Research and Innovation, OECD Publishing.10.1787/313a9b21-en.

Stephenson, W. (1953). The study of behavior; Q-technique and its methodology.

Sukk, M. \& Soo, K. (2018). EU Kids Onlineí Eesti 2018. Aasta Uuringu Esialgsed Tulemused, Ühiskonnateaduste instituut, Tartu, www.yti.ut.ee.

\section{THE DATAFICATION OF CHILDHOOD AT HOME: THE DATA PRACTICES, MEANINGS AND AFFECTS OF PARENTS OF YOUNG CHILDREN.}

Giovanna Mascheroni, Università Cattolica del Sacro Cuore, Milan, Italy

Lorenzo Zaffaroni, Università Cattolica del Sacro Cuore, Milan, Italy

"We are all now datafied - but children growing up today are among the first to be datafied from birth." (Children's Commissioner, 2018, p. 11). Concern is high regarding 
the short-term and especially long-term social and political consequences of datafication for children's life chances.

However, empirical evidence on everyday life data-practices and their meanings for children, families and communities is still sparse, especially in Italy. While datafication represents a radicalization of the commodification of childhood, we cannot understand it only as a top-down process, driven by corporations adhering to the logic of surveillance capitalism (Zuboff, 2015). Rather, the datafication of childhood is also a bottom-up practice, initiated by a variety of actors, for different purposes and with different meanings. Children today do not encounter automated data collection and algorithmic calculation systems only as a result of their direct engagement with digital media. Data about children is generated and shared by parents and other family members, and, increasingly, by a number of internet-connected devices at home and at school. The datafication of childhood, then, is further expanded by two simultaneous and interdependent developments: namely, the domestication of Internet of Things (IoT) devices and the mediatization of parenthood (Damkjaer, 2018; author, 2018). Numerous loTs are designed and marketed for the child and the family, including: wearable technologies for the monitoring of biometrics; the Internet of Toys (author, 2019) robots, talking pets and dolls, smart building blocks, etc.; smart watches to track children's whereabouts; virtual home assistants and other domestic internet-connected appliances. Being fitted with sensors and connected to networks is the pre-condition for objects to take part in the datafication of family life. Indeed, sensors and connectivity turn things into media (Bunz \& Meikle, 2018; author, 2019) that potentially mediate the most mundane and most intimate aspects of family life, such as children's conversations with their dolls. As a result, our homes are refashioned as "datafied environments" (Hintz, Dencik \& Wahl-Jorgensen, 2018).

loTs and loToys are domesticated in the context of an increasingly mediatized performance of parenthood. Indeed, many expecting couples now ritually mark the transition to parenthood in the form of ultrasound images shared on social media (Leaver, 2017). Moreover, a growing number of mothers use pregnancy apps to monitor their foetus' development and track their own health parameters (Lupton \& Pederson, 2016). Mediatized parenting practices (author, 2018) continue after birth, whether in the form of sharenting - that is, the (semi)public sharing of family photographs and videos on social media (Autenrieth, 2018; Blum-Ross \& Livingstone, 2017; Damkjaer, 2018); or through the use of parenting apps and wearables to monitor infants' health, or sleeping and feeding patterns (author, 2019). We can define such practices as "intimate surveillance" (Leaver, 2017) or "caring dataveillance" (Lupton, in press) to emphasise the entanglement of caring and dataveillance (the surveillance enabled by digital technologies and data analytics) in the contemporary practices and imaginaries of "good parenting". Once parenting becomes mediatized and reliant on technologies of caring and sharing, it is simultaneously imbued with a data-driven business logic called "surveillance capitalism" (Zuboff, 2015).

However, existing research shows the ambivalent meanings of datafication for parents and children and suggests that the messiness, uncertainty and taken for grantedness of everyday life generates complex entanglements of data and practices. For example, Lupton's (in press) work on pregnancy and parenting apps points to the diverse agential 
capacities that are implicated in the practices of caring dataveillance, that is experienced by women also as empowering and an expression of love. Similarly, Barassi (2018) finds that "children are being profiled on the basis of highly contradictory, inaccurate and imprecise data traces" (2018, p. 174), with parents failing to record systematically each and every behaviour. Algorithmic calculations and predictions, then, fit ill with the messy world of families. Autenrieth (2018) and Damkjaer (2018) show how parents appropriate, negotiate and even resist sharenting by inventing new photo practices that minimise children's data.

The DataChildFutures project aims to push forward the line of inquiry that analyses datafication at the level of the everyday, and generate a grounded understanding and novel theorisations of the datafication of childhood as a socially situated, everyday and embodied experience. It adopts a triangulation of methods, combining a survey of parents of 0- to 8-years-old children, a qualitative longitudinal research (QLR) with young children and their families, an ethnography of online parenting forums, blogs and social media (Hine, 2015), and a walkthrough (Light et al., 2018) of the affordances of apps, loTs and loToys used by children. This presentation will report on the first phase of the research - the survey of a national representative sample of parents - aimed at mapping mediatized parenting practices, children's practices (play, learning, communication) through and with digital media and loTs, parents' imaginaries. The survey will measure: family's demographics; access and use of the internet, touchscreens and loTs by parents; access and use of the internet, touchscreens and apps, loTs and loToys by children; children's digital play, literacy and communicative practices; parental mediation and scaffolding practices adopted by parents; intimate surveillance practices such as sharenting; parents' beliefs around the opportunities and risks of these technologies. The data analysis will identify which factors explained variations in a) children's digital practices, b) parent's intimate surveillance practices, and c) parental mediation. Factor and cluster analysis will be used to identify family types.

\section{References}

Autenrieth, U. (2018). Family photography in a networked age. Anti-sharenting as a reaction to risk assessment and behaviour adaption. In G. Mascheroni, C. Ponte, \& A. Jorge (Eds.), Digital Parenting: The Challenges for Families in the Digital Age (pp. 219231). Göteborg: Nordicom.

Barassi, V. (2018). The Child as Datafied Citizen. Critical Questions on Data Justice in Family Life. In G. Mascheroni, C. Ponte, \& A. Jorge (Eds.), Digital Parenting: The Challenges for Families in the Digital Age (pp. 169-177). Göteborg: Nordicom.

Blum-Ross, A., \& Livingstone, S. (2017). "Sharenting," parent blogging and the boundaries of the digital self. Popular Communication, 15(2), 110-125.

Bunz, M., \& Meikle, G. (2018). The Internet of Things. Cambridge: Polity Press. Children's Commissioner for England. (2018). Who knows what about me? A Children's Commissioner report into the collection and sharing of children's data. London: 
Children's Commissioner for England. Retrieved from:

https://www.childrenscommissioner.gov.uk/wp-content/uploads/2018/11/who-knowswhat-about-me.pdf

Damkjær, M. S. (2018). Sharenting = Good Parenting? Four Parental Approaches to Sharenting on Facebook. In G. Mascheroni, C. Ponte, \& A. Jorge (Eds.), Digital Parenting: The Challenges for Families in the Digital Age (pp. 209-218). Göteborg: Nordicom.

Harris, R. (2017). 72M data points collected on children in spite of COPPA. App Developer Magazine, 27 December. Retrieved from: https://appdevelopermagazine.com/5769/2017/12/27/72m-data-points-collected-onchildren-in-spite-of-coppal

Hine, C. (2015). Ethnography for the Internet: Embedded, Embodied and Everyday. London: Bloomsbury.

Hintz, A., Dencik, L., \& Wahl-Jorgensen, K. (2018). Digital Citizenship in a Datafied Society. Cambridge: Polity.

Leaver, T. (2017) Intimate Surveillance: Normalizing Parental Monitoring and Mediation of Infants Online. Social Media + Society, 3(2).

Lupton, D., \& Pedersen, S. (2016). An Australian survey of women's use of pregnancy and parenting apps. Women and Birth, 29(4), 368-375.

Zuboff, S. (2015). Big other: surveillance capitalism and the prospects of an information civilization. Journal of Information Technology, 30(1), 75-89.

\title{
“GOVERNING” SHARENTING: PARENTS' PRIVACY CONCERNS AND THE GOVERNANCE OF CHILDREN'S SOCIAL MEDIA PRESENCE
}

\author{
Davide Cino, \\ Università Cattolica del Sacro Cuore, Milan, Italy \\ Ellen Wartella, \\ Northwestern University
}

"Sharenting", or "sharing representations about one's parenting or children online" is a usual habit for families in the digital age (Blum-Ross \& Livingstone, 2017). This practice is part of a broader process of datafication of the everyday life for many families, where information and representations ranging from one's pregnancy to accounts of children's lives are transformed into online data (Mascheroni, 2018). 
This study explores how parents govern their children's social media presence when not only parents, but also adults from external systems share about them. As such, we administered a survey to a sample of 300 American parents focusing on four main areas: parents' pre- and post-birth sharing experiences; parents' use of privacy settings and alternative ways of sharing; parents' concerns and digital dilemmas about sharenting; parental agency and management of sharing about children from external systems (i.e. extended family members, schools, and teachers).

Descriptive results show that the majority of parents in our sample start sharing about their children before they are born and continue to do so as they grow, with number of pictures in the span of a month ranging from 1 to $100+$. Most parents are on the same page with their partners about rules to share, and use restrictive privacy settings, but few have opted for alternative ways of sharing (e.g. Tiny Beans). Only one third of respondents have questioned their photo-sharing behaviors, which lead in some cases to removing a social media post about their children. Few have asked for their children's permission before sharing (when age would allow to do so). Finally, the majority of respondents feel like it is their job to be in control of their children's digital footprints and deem unacceptable for people external to the nuclear family, like relatives and teachers, to share about their kids, interpreting such occurrences as a privacy violation. Still, few have set preventive boundary rules.

Further, we measured parents' level of privacy concern using a four-item scale focusing on parents' worries about possible consequences of their photo-sharing behavior with respect to risks such as digital kidnapping, bullying, conversion of the pictures into child pornography, and the use of children's data by corporations. The analysis will show how different level of privacy concerns relate to different styles of governance with respect to parents' own and people's from external systems sharing behavior.

Implications of these findings are discussed in terms of children's rights in light of what we conceptualize as the double loss of agency which may result from sharenting. When parents share about their children, in fact, a first-level loss of agency occur as the child has not control of the process. When it is other adults who share about the child, a second-level loss of agency takes place as parents, as children's personal information gatekeepers (Steinberg, 2016), may lose track of their kids' digital breadcrumbs.

\section{References}

Blum-Ross, A., \& Livingstone, S. (2017). "Sharenting," parent blogging, and the boundaries of the digital self. Popular Communication, 15(2), 110-125.

Mascheroni, G. (2018). Datafied childhoods: contextualising datafication in everyday life. Current Sociology, 1-16.

Steinberg, S. B. (2016). Sharenting: Children's privacy in the age of social media. Emory LJ, 66, 839-884. 